\title{
Fatores que levam os surdos a fazerem o "Turnover" nas empresas de grande porte do Sul Fluminense
}

\section{Reasons that lead the deaf to form the "Turnover" in large companies in the southeast of Rio de Janeiro State}

Artigo

Original

\author{
Bruna Viana de Abreu Gonçalves ${ }^{1}$ \\ Douglas Baltazar Gonçalves² \\ Ivanete da Rosa Silva de Oliveira ${ }^{3}$
}

Original

Paper

\section{Palavras-chave:}

Turnover

Surdos

Mercado de Trabalho

Deficiente

\section{Resumo}

A rotatividade de empregados em uma organização é prejudicial tanto para a empresa como para o trabalhador e quando extrapola os limites da normalidade é chamado de turnover. A mudança dos funcionários gera prejuízos de capital intelectual e financeiros para as organizações. Este artigo procura destacar que o turnover acontece, na maioria das vezes, com funcionários deficientes que, por diversos fatores geram ações de remanejamento de pessoal, por isso, é essencial que ocorra o treinamento para a inclusão do deficiente no mercado de trabalho. O presente trabalho apresentará os fatores que levam os surdos a fazerem turnover nas empresas de grande porte da região Sul Fluminense.

\section{Abstract}

The employee turnover in an organization is harmful to both the company and the employee and when exceeds the limits of normality it is called turnover. The change of employees generates losses of financial and intellectual capital to the organizations. This article aims to emphasize that turnover happens most often with disabled employees that for several reasons cause personnel reallocation, so it is essential a training to the inclusion of the disabled into the labor market. This paper presents the reasons that lead the deaf to form the "turnover" in large companies in the southeast of Rio de Janeiro State.
Key words:

Turnover

Deaf

Job Market

Deficient

\footnotetext{
${ }^{1}$ MBA em Gestão Empresarial e Negócios - Graduação em Comunicação Social - Habilitação em Publicidade e Propaganda

${ }^{2}$ Mestrando em História - Pós Graduação em Comunicação Empresarial - Graduação em Comunicação Social - Habilitação em Jornalismo

${ }^{3}$ Doutoranda em Políticas Públicas - Mestrado em Educação Física - Graduação em Pedagogia e em Educação Física
}

Recebido em 03/2011

Aprovado em 04/2011 


\section{Introdução}

A inclusão das pessoas portadoras de deficiências auditivas teve avanços significativos nesse último século. Cabe destacar a análise de quais os fatores que levam os surdos a fazerem o "turnover" nas empresas de grande porte do Sul Fluminense.

Este artigo é o resultado de pesquisa de campo- promovida por um questionário fechado e aberto, aplicado em um ambiente organizacional com portadores de deficiências especiais auditivo em seu quadro de colaboradores- retratando a visão humana organizacional dessa temática.

Este estudo trata-se de uma pesquisa de campo exploratória, de cunho predominantemente qualiquantitativa, pois, pretende-se, através de autores renomados da área, demonstrar, juntamente com os dados analisados na pesquisa feita, quais são os objetivos dos surdos fazerem o "turnover" nas empresas.

O presente artigo tem como relevância analisar as organizações que queiram reter seus capitais intelectuais evitando prejuízos financeiros - seleção e recrutamento, indicadores gerenciais, treinamento etc. - através da melhoria na estrutura organizacional para portadores de deficiência dentro da empresa.

Para discutir a questão da inclusão do surdo na sociedade, utilizaremos Graeff (2006, p.23):

\begin{abstract}
A atualidade aponta para questões urgentes da dinâmica social. Entre essas questões, a busca pela inclusão dos surdos possibilita discussões de diferentes ordens, quais sejam, financeira, mercadológica, técnica, pessoal e idealística.
\end{abstract}

Muitas vezes, pelo desconhecimento, as pessoas divagam e criticam um surdo; porém, desconhecem que eles possuem uma linguagem, uma comunidade unida e organizada, e principalmente têm as mesmas condições cognitivas que os ouvintes, o que significa que a surdez não impede que estes sujeitos possam fazer parte atuante na sociedade.

O presente trabalho tem como objetivo defender que, atualmente, a surdez é uma deficiência que poderá acarretar múltiplas consequências sob os mais variados prismas, para o sujeito que se enquadra nessa situação. Pimenta
(2001, p. 24 apud Graeff, 2006, p.23) descreve a declaração de ator surdo Brasiliense:

\begin{abstract}
A surdez deve ser reconhecida como apenas mais um aspecto das infinitas possibilidades da diversidade humana, pois ser surdo não é melhor ou pior do que ser ouvinte é apenas diferente. Se considerarmos que surdos não são "ouvintes com defeito", mas, pessoas diferentes, estaremos aptos a entender que a diferença física entre pessoas surdas e pessoas ouvintes gera uma visão diferente de mundo, um 'jeito ouvinte de ser' e um 'jeito surdo de ser', que nos permite falar em uma cultura da visão e outra da audição.
\end{abstract}

Através da pesquisa exploratória é proporcionado mais familiaridade com o problema da inclusão de portadores de necessidades especiais nas empresas, devido a Lei $n^{\circ} 8.213$ de 24 de julho de 1991, que se dá, às vezes, de maneira imprópria, gerando uma alta rotatividade de surdos dentro das empresas de nossa região, o que acarreta prejuízos intelectual e financeiros para as organizações. Trata-se de um tema em constante evolução, sendo necessárias frequentes atualizações.

No Brasil, a legislação sobre acesso de pessoas com deficiência ao trabalho entrou em vigor há mais de 14 anos, mais precisamente nas Leis $\mathrm{n}^{\circ} 8.112$, de 11 de dezembro de 1990, que define em até $20 \%$ o percentual de vagas em concursos públicos, e n ${ }^{\circ} 8.213$, de 24 de julho de 1991, que determina uma cota de vagas para a pessoa com deficiência, variando de 2 a $5 \%$, junto às empresas privadas com mais de 100 funcionários (BRASIL, 1999a; 1999b).

A reserva de vagas para o setor privado surgiu posteriormente, e está prescrita na lei $\mathrm{n}^{0} 8.213$, de 24 de julho de 1991 (BRASIL, 1991), que dispõe sobre os planos e benefícios da Previdência, art. 93, prescreve: a empresa com 100 (cem) ou mais empregados está obrigada a preencher de $2 \%$ (dois por cento) a $5 \%$ (cinco por cento) dos seus cargos com beneficiários reabilitados ou pessoas portadoras de deficiência, habilitadas, na seguinte proporção: 
I- até 200 empregados - $2 \%$

II- de 201 a 500 - 3\%

III- de 501 a 1000 - 4\%

IV- de 1000 em diante - 5\%

\section{A inclusão social dos deficientes auditivos}

Existem no Brasil 24 milhões de pessoas portadoras de deficiência, o que significa cerca de $14 \%$ da população. Entre elas, 5,7 milhões são pessoas com deficiência auditiva (Censo IBGE 2000). Essas pessoas encontram-se excluídas, de diversas formas, de várias dimensões da vida social e produtiva.

O grande desafio da sociedade, atualmente, é a inclusão social dos portadores de deficiência. Os surdos têm uma grande dificuldade de ler e entender a língua escrita, o que dificulta ainda mais a colocação dos mesmos na sociedade, conforme afirma a Sá (2006, p.2) em sua definição de surdo:

\begin{abstract}
Quanto ao termo "surdo", podemos dizer que é o termo com o qual as pessoas que não ouvem referem-se a si mesmos e a seus pares. Podemos definir uma pessoa surda como aquela que vivencia um déficit de audição que o impede de adquirir, de maneira natural, a língua oral/auditiva usada pela comunidade majoritária e que constrói sua identidade calcada principalmente nesta diferença, utilizando-se de estratégias cognitivas e de manifestações comportamentais e culturais diferentes da maioria das pessoas que ouvem.
\end{abstract}

A população surda no mundo de hoje é muito extensa, sendo que a surdez pode ser uma doença de nascença, como também pode ocorrer pelo fato de uma outra doença deixar sequelas ou por uma doença na infância e na juventude. Quanto ao momento de aparecimento da Surdez, as deficiências auditivas são classificadas de acordo com a aquisição da linguagem e da capacidade de leitura. Quem define bem essa diferença é Oliveira, Castro, Ribeiro (2002, p.2):

A Surdez Pós-lingual surge quando a criança já fala e lê, não se acompanhando praticamente de regressão devido ao suporte da leitura. A Surdez Peri-lingual surge nas crianças que falam, mas que ainda não leem, situação em que, se não existir um acompanhamento eficaz, se dá uma rápida degradação da linguagem. A Surdez Pré-lingual é caracterizada pela total ausência de memória auditiva, sendo por isso extremamente difícil a estruturação da linguagem.

Segundo a Organização Mundial da Saúde (OMS), cerca de $10 \%$ da população mundial (perto de 600 milhões de pessoas) são portadoras de alguns tipos de deficiência. Estima-se que a distribuição desse percentual de PPDs (pessoas portadoras de deficiência) em nível médio mundial, seja de 5\% com deficiência mental, $2 \%$ com deficiência física, $1,5 \%$ com deficiência auditiva, $1 \%$ com deficiência múltipla e $0,5 \%$ com deficiência visual. Nos países subdesenvolvidos ou em vias de desenvolvimento, esse número pode chegar a $20 \%$ da população e somente 1 a $2 \%$ destas pessoas têm algum tipo de serviço de assistência, readaptação, acompanhamento clínico, psicológico, inclusão no trabalho etc.

\section{A inserção no mercado de trabalho: desafios para pessoas surdas}

A colocação dos deficientes auditivos no mercado de trabalho gera um grande investimento para as empresas e isso acarreta ao empresário um alto custo, sendo assim, falta uma estrutura nas empresas para uma boa relação entre funcionário, deficiente e chefe.

$\mathrm{Na}$ maioria das vezes tem que ser utilizado uma segunda língua para a relação entre um funcionário e um deficiente, sendo que, a língua principal do surdo é a Libras e para que um funcionário compreenda essa língua, é necessário um curso extra, que na maioria das vezes não é oferecido pela empresa. A Federação Nacional de Educação e Integração dos Surdos (FENEIS) é uma entidade filantrópica, sem fins lucrativos com finalidade sóciocultural, assistencial e educacional que tem por objetivo a defesa e a luta dos direitos da Comunidade Surda Brasileira e a sua revista explica bem a língua de Libras:

\section{(1)}


A LIBRAS, como toda Língua de Sinais, é uma língua de modalidade gestual-visual porque utiliza, como canal ou meio de comunicação, movimentos gestuais e expressões faciais que são percebidos pela visão; portanto, diferencia-se da Língua Portuguesa, que é uma língua de modalidade oral-auditiva por utilizar, como canal ou meio de comunicação, sons articulados que são percebidos pelos ouvidos. Mas, as diferenças não estão somente na utilização de canais diferentes, estão também nas estruturas gramaticais de cada língua. (p. 7)

O maior problema dos surdos é a dificuldade de comunicação e não da surdez em si mesma. Parte de seus problemas de comunicação vem do fato de ser-lhes impossível adquirir a linguagem partindo de um modelo exclusivamente oral auditivo. Isso não quer dizer que o surdo não possua competência linguística, pelo contrário: há estudos que demonstram que crianças surdas procuram sempre criar e desenvolver uma linguagem.

A dificuldade dos surdos em encontrar um trabalho parte do reconhecimento das habilidades pela classe empresarial até a dificuldade de cursos profissionalizantes adequados para esses sujeitos. Segundo o site da FENEIS:

A contratação do surdo é o investimento para a empresa, pois ocorre o aumento da atenção concentrada no ambiente de trabalho; valorização do emprego pelo surdo pela dificuldade de inserção no mercado de trabalho; descoberta de talentos desconhecidos e potenciais diversificados e enriquecimento do grupo funcional. Com a inclusão de surdos o grupo será multidisciplinar, contribuindo para a sobrevivência da empresa e gerando resultados de satisfação e motivação, uma vez que acreditamos que o fator chave para obter uma vantagem competitiva está na diversidade do quadro funcional, pois ocorre: maior capacidade para atender o mercado globalizado; enriquecimento do ambiente de trabalho; estímulo da criatividade de trabalho e como consequência aparecimento de novas soluções; satisfação dos funcionários e redução do Turn Over (Rotatividade).
$\mathrm{O}$ que deixa as empresas mais arrasadas é quando há um grande investimento no funcionário surdo e, após vários cursos e treinamentos entre a equipe, acontece o chamado turnover (rotatividade) e esse funcionário pede para sair da empresa, utilizando todo o aprendizado oferecido por outro investimento, como mostra o site da RH Central:

As empresas estão procurando ajuda, pois, o turnover de pessoas com deficiência nas organizações é muito grande, o que mostra a contratação, porém, uma forte dificuldade de adaptação. Não é só incluir, mas manter a pessoa lá dentro e a sensibilização é a melhor forma de fazer com que as pessoas se relacionem melhor. Quando um funcionário sem deficiência percebe que a empresa dele coloca um funcionário com deficiência na sua equipe, ele vê que a sua organização respeita as diversidades; dessa forma, se sentirá mais à vontade para expor as suas diferenças.

As pessoas com diferença no mercado têm muito a acrescentar nas empresas hoje em dia. Elas trazem mais paciência, tolerância e humildade para o meio de trabalho. Essas pessoas terão necessidade de apoio e também darão um retorno a toda ajuda recebida. Com isso, os trabalhadores que estão à sua volta passarão a se sentir mais úteis, afirma CLEMENTE e CELESTINI.

Segundo Pastore (2000, p.7):

Os portadores de deficiência têm uma vida cercada de alegrias, realizações, incertezas e dificuldades e é dentro desse cenário que crescem, se educam, fazem amigos e constroem suas carreiras, porem são vítimas de preconceitos, principalmente porque são vistas como dependentes e incômodas.

Pode-se observar que uma parte da redução da capacidade de andar, pensar, aprender, falar ou ver está ligada realmente às limitações do deficiente, no entanto, o meio social impõe diversas barreiras para as pessoas surdas. Com a mudança desse quadro, de forma a proporcionar condições adequadas a essas pessoas e elas deixariam de ser tratadas como um deficiente.

Os empresários e recrutadores que são responsáveis pela contratação de deficientes 
nas empresas precisam adquirir uma visão mais realista, de forma a ampliar as oportunidades de trabalho das pessoas que portam limitações.

As empresas, muitas vezes, não oferecem os mesmos direitos para os funcionários portadores de deficiência, fazendo com que estes fiquem desestimulados, não deixando-os participarem de promoções, aumentos salariais e bônus por performance. $\mathrm{O}$ surdo tem que trabalhar mais em relação aos demais funcionários para conseguir um bom salário, devido as suas limitações. No modelo social de deficiência, segundo Sassaki (1997):

O número de pessoas com deficiência em idade economicamente ativa que estão fora da força de trabalho é muito grande. E as empresas devem contratar trabalhadores com deficiência, em conformidade com aspolíticas de emprego, salários e benefícios da empresa, e por estarem capacitadas e não apenas para cumprir leis. Esses trabalhadores constituem-se, em mão de obra tão produtiva quanto a constituída só de trabalhadores sem deficiência.

\section{Metodologia}

Este estudo trata-se de uma pesquisa de campo exploratória, de cunho predominantemente qualiquantitativa, através de pesquisa fechada e aberta, pois se pretende, através de autores renomados da área, demonstrar, juntamente com os dados analisados na pesquisa feita, quais são os fatores que levam os surdos a fazerem o "turnover" nas empresas de grande porte do Sul Fluminense.

O método utilizado foi pesquisa bibliográfica e pesquisa de campo, na qual é entrevistado portadores de deficiência auditiva no contexto organizacional. A escolha do questionário fechado para a pesquisa com os surdos deveu-se ao fato de que, para uma análise na qual os deficientes conseguissem responder com eficácia e mais precisão, ter-se-ia que utilizar uma ferramenta em que o resultado fosse mais direto.

Já a escolha do questionário aberto foi ideal para analisar os motivos que levam os surdos a se manterem e a saírem das empresas, com respostas pequenas ideais para os portadores de necessidades.
O estudo foi realizado baseado nos resultados obtidos na pesquisa de campo, que abrangeu uma amostra de 20 funcionários, subdivididos em 4 empresas diferentes.

A pesquisa levantou dados sobre questões relacionadas diretamente com a inclusão dos surdos no ambiente organizacional, pesquisados através de questionário fechado e aberto.

$\mathrm{O}$ resultado da pesquisa relacionada refere-se especificamente a abordagem da sensibilidade de todos participantes na inclusão dos surdos no mercado de trabalho, de forma a diminuir os preconceitos e, consequentemente, os turnover nas empresas, mudando o comportamento dos funcionários no ambiente organizacional, como destaca: [...] a visão preconceituosa que patrões e colegas de trabalho costumam lançar sobre essa parcela da população. A maioria as vê com pena ou as considera incapazes [...] (CLEMENTE, 2003: 61)

As empresas podem aproveitar muito as pessoas com diferença no meio de trabalho. Essas pessoas terão necessidade de apoio e também darão um retorno a toda ajuda recebida. Com isso, os trabalhadores que estão à sua volta passarão a se sentir mais úteis. (CLEMENTE, 2003: 26)

Os resultados obtidos foram analisados e, com isso, observamos as causas que levam os surdos a fazerem turnover no ambiente organizacional, considerando o comportamento humano dentro das empresas.

\subsection{Resultados e Discussão}

A pesquisa confirma que $31 \%$ dos entrevistados possuem faixa etária entre 26 a 32 anos, ficando com $25 \%$ a idade de 18 a 25 anos e também $25 \%$ para os acima de 40 anos restando $19 \%$ entre 19 a 25 anos.

Foi observado também, com mais de $40 \%$, que a maioria dos funcionários surdos possuem o Ensino Médio Completo e, em contrapartida, mais de $30 \%$ possuem o Ensino Fundamental Incompleto.

Como ilustra a figura 1, a maioria dos entrevistados possui mais de 10 anos de experiência profissional e, logo em seguida, ficando os de 3 a 5 anos de experiência. 


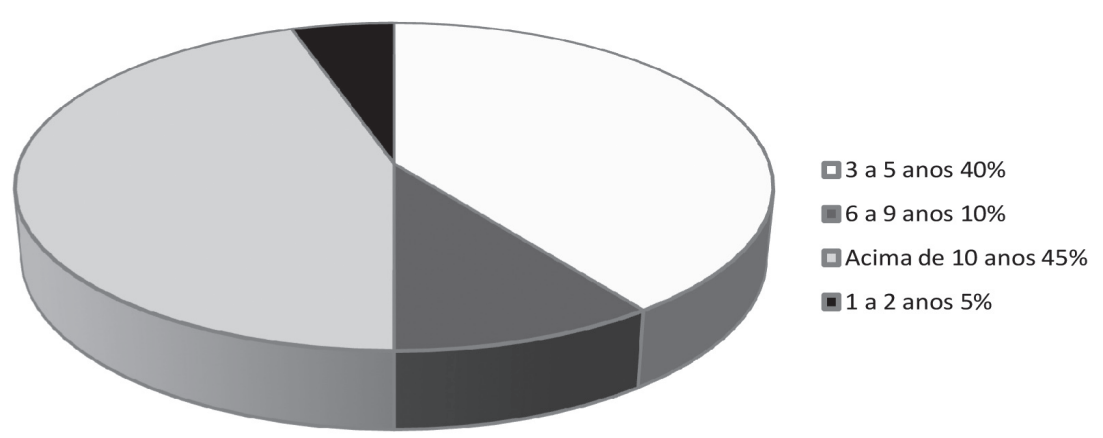

Figura 1. Representação Gráfica do tempo de experiência profissional dos entrevistados.

Como apresenta a figura 2, $50 \%$ dos entrevistados já trabalharam em 3 a 5 empresas distintas e mais de $30 \%$ de 6 a 9 empresas, ten- do um total de mais de $80 \%$ dos entrevistados que já trabalharam de 3 a 9 empresas.

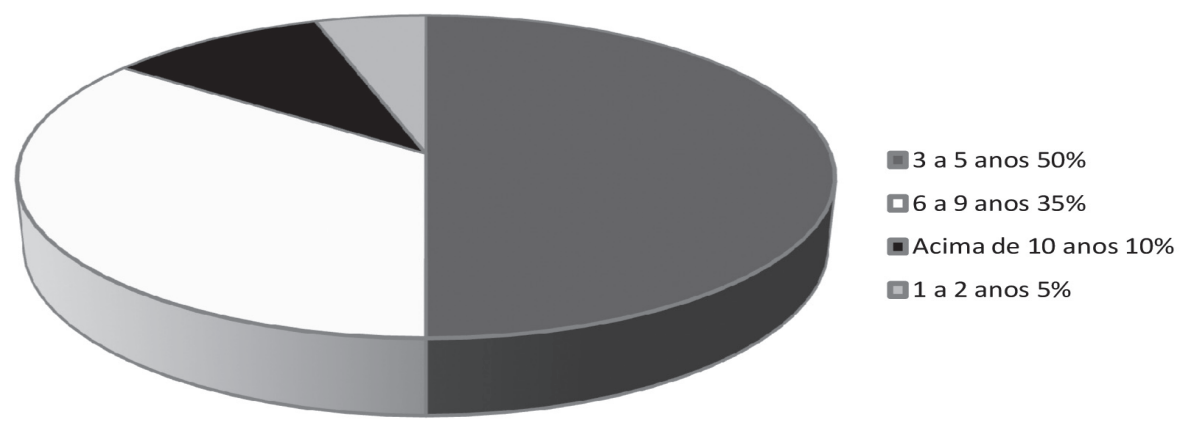

Figura 2. Representação Gráfica da quantidade de empresas que o entrevistado já trabalhou.

Segundo a figura 3 , foi feita uma correlação entre a quantidade de empresas que o surdo já trabalhou com o tempo de experiência que ele possui na sua carreira profissional. Somando um total de mais de $81 \%$ dos entrevistados que possuem de 3 a 5 anos de experiência e os acima de 10 anos, podemos afirmar que os mesmo já mudaram de empresas aproximadamente de 3 a 9 vezes.

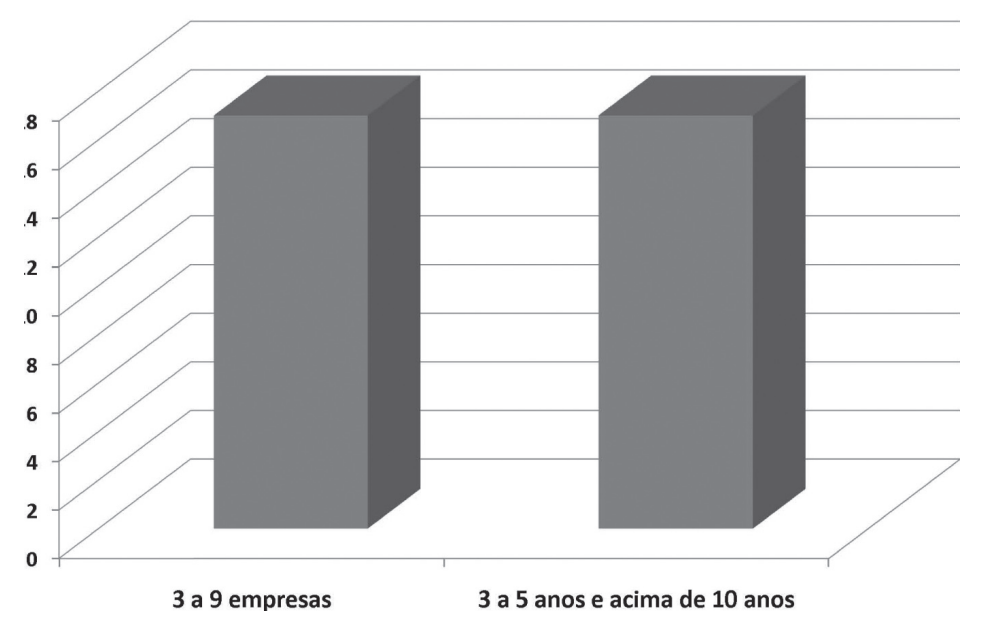

Figura 2. Representação Gráfica da correlação entre a quantidade de empresas que o surdo trabalhou e o tempo de experiência que ele possui. 
Analisando a figura 4, o tempo que o entrevistado possui na empresa atual, é possível confirmar que acima de $50 \%$ tem somente de 1 a 2 anos, e mais de $20 \%$ estão de 3 a 5 anos.
Isso confirma que os surdos não criam vínculo empregatício duradouro, aumentando a incidência do turnover na vida profissional.

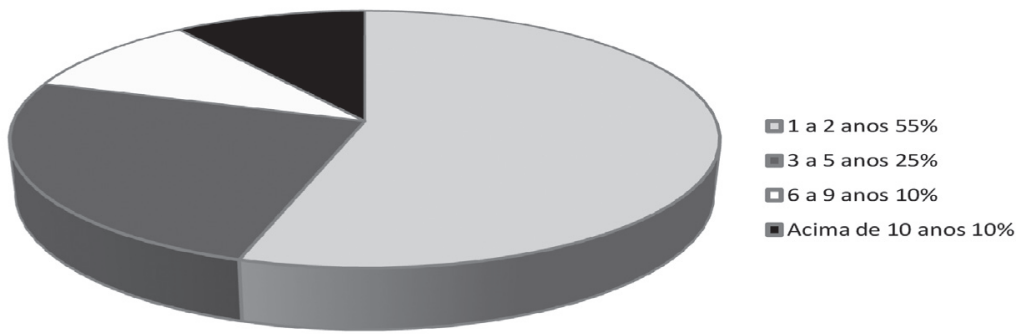

Figura 4. Representação Gráfica do tempo de serviço na empresa atual.

Devido ao pouco tempo de serviço que o surdo se mantém em cada empresa, conforme mostra o gráfico anterior, podemos afirmar que os entrevistados não estão totalmente insatisfeitos em seu emprego atual. Conforme análise feita, os profissionais auditivos se mantém nas empresas praticamente o tempo da sua inclu- são e adaptação, ou seja, é o tempo suficiente para uma boa satisfação no ambiente de trabalho, sendo que, quando começa a rotina diária ficar maçante, eles logo saem do emprego. Isso é confirmado na figura 5, que apresenta os empregados muito satisfeitos com $45 \%$, os pouco satisfeitos com $35 \%$ e os insatifeitos com $20 \%$.

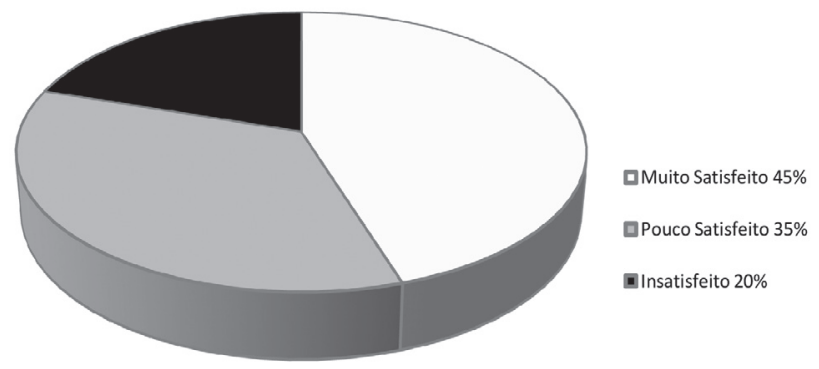

Figura 5. Representação Gráfica da satisfação da empresa atual.

Na pesquisa aberta foi possível notar os motivos relevantes que levam os surdos a se manterem e também a saírem do ambiente organizacional.

Segundo Robbins (2004: 262):

Uma das descobertas mais bem documentadas nas pesquisas sobre comportamento organizacional e individual é que tanto as organizações como seus membros resistem à mudança. Em certo sentido, trata-se de algo positivo, ao oferecer estabilidade e previsibilidade ao comportamento. Se não houvesse resistência, o comportamento organi- zacional se revestiria de uma aleatoriedade caótica. A resistência também pode ser fonte de conflitos funcionais. Entretanto, existe uma desvantagem inequívoca na resistência: ela dificulta a adaptação e o progresso.

Para que não ocorresse o turnover, foram notados os seguintes pontos relacionados ao funcionário surdo: um plano de cargo salarial, a estrutura organizacional para a inclusão no setor de trabalho e principalmente a integração com os outros colaboradores que são ouvintes. Dessa maneira, o funcionário fica estimulado e não terá interesse de trocar de emprego. 


\section{Conclusão}

Hoje em dia, as organizações estão se preocupando cada vez mais com as questões da responsabilidade social, no entanto, não podemos deixar de lado as questões "humanas", pois, sabemos que a inclusão das pessoas nas mudanças é essencial para que as mesmas ocorram com sucesso.

Atualmente, existe um movimento de inclusão social que consequentemente traz um mundo mais democrático, em que temos que respeitar os direitos e deveres de todos e ter consciência de que a limitação não diminui os direitos do indivíduo.

As pessoas portadoras de limitações são cidadãos incluídos na mesma sociedade e, por isso, ela deve se preparar para lidar com a diversidade humana. $\mathrm{O}$ meio social deve respeitar e aceitar a todos, sem preconceitos de raça, cor, religião, sexo, idade, origens étnicas, opção sexual e suas deficiências. Uma sociedade democrática aberta a todos estimula a participação de cada um, reconhece o potencial dos cidadãos, estimulando as diferentes experiências humanas.

A sociedade inclusiva tem o objetivo de oferecer oportunidades semelhantes a todos, propiciando a igualdade na diversidade. É um meio democrático que reconhece todos os seres humanos como livres e com o direito de exercer sua cidadania.

Podemos concluir que devemos incluir as pessoas portadoras de deficiência no mercado de trabalho, e isso acarreta uma extrema necessidade para que as empresas assegurem condições de interação entre os surdos com os demais funcionários das empresas bem como com todos os parceiros e clientes, mas é necessário que seja principalmente valorizada suas particularidades.

Se o turnover da organização for maior que $5 \%$, indica que algo está errado. A rotatividade traz malefícios à empresa, e para que haja uma diminuição nessa situação, é preciso atender as necessidades e criar vínculos dinâmicos de relacionamento com os colegas de trabalho, chefes, clientes e fornecedores.

$\mathrm{O}$ turnover não traz vantagens nem para a empresa e nem para o funcionário. A empresa tem despesas de: rescisão de contrato de trabalho, recrutamento, seleção, treinamento, adaptação e outras despesas variáveis (advogados, justiça do trabalho, etc.).

A pesquisa mostrou que a superação do preconceito é uma tarefa difícil que exige educação, treinamento e compreensão tanto do lado não portador quanto do portador de deficiência.

Conclui-se que, pra que ocorra a inclusão do deficiente no mercado de trabalho é necessária a mudança cultural, sendo que, essa transação não é simples, pois se trata de alterar os mecanismos que mexem com variáveis essenciais ao comportamento humano.

\section{Referências bibliográficas}

BRASIL. Ministério do Emprego e do Trabalho. Lei 8112 de 11 de dezembro de 1990. Legislação relativa ao trabalho de pessoas portadoras de deficiência: coletânea. Brasília: MTE, SIT/DSST, 1999c.

BRASIL. Ministério do Emprego e do Trabalho. Lei 8213 de 24 de julho de 1991.

Legislação relativa ao trabalho de pessoas portadoras de deficiência: coletânea. Brasília: MTE, SIT/DSST, 1999d.

ClEMENTE, C. A; CELESTINI, E. C. Trabalhando com a diferença: responsabilidade social e inclusão de portadores de deficiência. São Paulo: Espaço da Cidadania, 2004.

Trabalho e inclusão social de portadores de deficiência. 1. ed. Osasco: Gráfica e Editora Peres, 2003.

\section{EMPRESAS DEFICIENTES PARA}

A INCLUSÃO. Disponível em: http:// www.rhcentral.com.br/pen/pen.asp?cod_ materia $=3819$ Acessado em: 05/08/2010

GRAEFF, Talita Diane. A relação do surdo com o mercado de trabalho. Revista Conexão UEPG, v. 2, p. 23-28, 2006.

IBGE. Censo demográfico 2000: resultados preliminares. Rio de Janeiro, 2000. 156 p. Tab. Graf. Mapas. Inclui 1 CD-ROM.

OLIVEIRA, Pedro; CASTRO, Fernanda; RIBEIRO, Almeida. Surdez infantil. Revista Brás Otorrinolaringol: 2002. 
PASTORE, José. Oportunidade de trabalho para Portadores de Deficiência. São Paulo:

Editora LTr. 2000.

REVISTA DA FENEIS. Rio de Janeiro: 1999 / 2002. Números 1 ao 13.

RIBEIRO, Mauro. Contratar um PPD (Profissional Portador de Deficiência?) s/d. Disponível em: http://www.institutomvc.com. br/costacurta/artmr01_ppd.htm Acessado em: 04.08 .2010

ROBBINS, Stephen Paul. Fundamentos do comportamento organizacional. São Paulo: Prentice Hall, 2004.

SÁ, Nídia Limeira de. Cultura, poder e educação de surdos. São Paulo: Paulinas, 2006.

SASSAKI, Romeu Kazumi. Inclusão: Construindo uma sociedade para todos. Rio de Janeiro: WVA, 1997.

Endereço para Correspondência:

Bruna Viana de Abreu Gonçalves

brunavianadeabreu@hotmail.com

Rua Ivair Stabellini, n $^{\circ} 90$

Bairro de Fátima - Barra do Piraí - RJ

CEP: 27.165-000

Informações bibliográficas:

Conforme a NBR 6023:2002 da Associação Brasileira de Normas Técnicas (ABNT), este texto científico publicado em periódico eletrônico deve ser citado da seguinte forma: GONÇALVES, Bruna Viana de Abreu; GONÇALVES Douglas Baltazar; OLIVEIRA Ivanete da Rosa Silva de Fatores que levam os surdos a fazerem o "Turnover" nas empresas

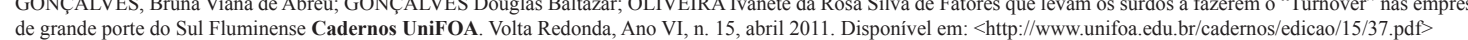

